Correction

\title{
Correction: Barmparesos et al. Indoor Air Quality and Thermal Conditions in a Primary School with a Green Roof System. Atmosphere, 2018, 9, 75
}

\author{
Nikolaos Barmparesos ${ }^{1} * \mathbb{D}$, Margarita Niki Assimakopoulos ${ }^{1}$, Vasiliki D. Assimakopoulos ${ }^{2}$, \\ Nikolaos Loumos ${ }^{1}$, Maria Aliki Sotiriou ${ }^{1}$ and Athanasios Koukoumtzis ${ }^{1}$ \\ 1 Department of Applied Physics, Faculty of Physics, University of Athens, Building Physics 5, \\ University Campus, 15784 Athens, Greece; masim@phys.uoa.gr (M.N.A.); \\ loumos_nick@hotmail.com (N.L.); avenir16@hotmail.com (M.A.S.); a.koukoumtzis@yahoo.com (A.K.) \\ 2 Institute for Environmental Research and Sustainable Development, National Observatory of Athens, \\ Lofos Koufou, 15236 Athens, Greece; vasiliki@noa.gr \\ * Correspondence: nikobar@phys.uoa.gr; Tel.: +30-210-727-6845
}

Received: 22 October 2018; Accepted: 23 October 2018; Published: 25 October 2018

The authors would like to correct the published article [1] concerning acknowledgments as follows:

The authors would like to thank the Ministry of Education, Research and Religious Affairs of Greece for licensing the experiment and moreover the direction of the 2nd primary school of Nea Smyrni for their cooperation and contribution to the measurements. This project has received funding from the European Union's Horizon 2020 research and innovation program under the Marie Skłodowska-Curie grant agreement No 645677.

\section{References}

1. Barmparesos, N.; Assimakopoulos, M.N.; Assimakopoulos, V.D.; Loumos, N.; Sotiriou, M.A.; Koukoumtzis, A. Indoor Air Quality and Thermal Conditions in a Primary School with a Green Roof System. Atmosphere 2018, 9, 75. [CrossRef]

(C) 2018 by the authors. Licensee MDPI, Basel, Switzerland. This article is an open access article distributed under the terms and conditions of the Creative Commons Attribution (CC BY) license (http://creativecommons.org/licenses/by/4.0/). 